
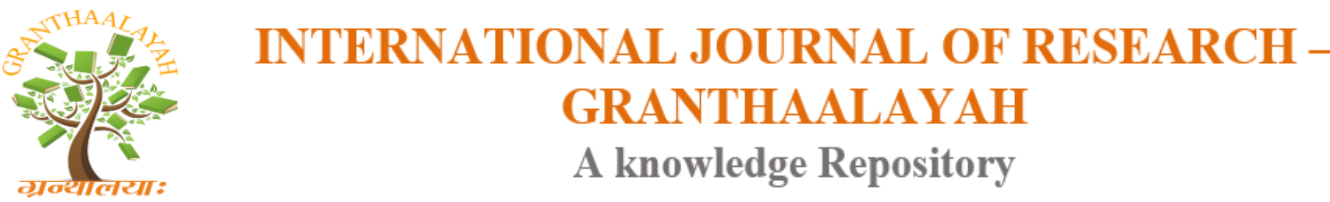

Science

\title{
INVESTIGATION OF LEISHMANIASIS VECTORS IN EL-KADOBA VILLAGE, WHITE NILE STATE, SUDAN
}

\author{
Belal Abdallah A. Adam ${ }^{1}$, Moawia Mukhtar Hassan ${ }^{2}$, Osman Mohammed Abd elnour ${ }^{3}$, \\ Ahmed Hamid Awadallah ${ }^{4}$ \\ ${ }^{1}$ Ph.D., Assistant Professor, Shendi University, Faculty of Public Health, Environmental Health \\ Department, Shendi, Sudan \\ ${ }^{2}$ Ph.D., Assistant professor, Epidemiology Department, Tropical Medicine Research Institute, \\ National Centre for Research, Sudan \\ ${ }^{3}$ Ph.D., Assistant Professor, Department of Entomology, National Laboratory, Sudan \\ ${ }^{4}$ MPH, Public Health Officer, Ministry of Health, Environmental Health Department, White Nile \\ State - Sudan
}

DOI: https://doi.org/10.29121/granthaalayah.v5.i1.2017.1938

\begin{abstract}
Visceral leishmaniasis (VL; kala-azar) is one of the most important parasitic tropical diseases in Sudan and the Sudan is considered to be one of the most important foci in the world. The visceral leishmaniasis has been described in Sudan since the beginning of the twentieth century. In Sudan, VL is caused by Leishmania donovani complex: MON 18, MON 30 and MON 82 zymodemes and The proven vector is Phlebotomus (Larroussius) orientalis, in this study a survey was carried out to identify the principal vector of VL based on Leishmania infection, morphological characters and to determine some ecological aspects of the sand flies prevalent in the area. Ten species of sand flies were recorded, three Phlebotomus species and seven Sergentomyia species of these sandflies, P. rodhaini was collected only from Acacia seyal/Balanities aegyptiaca at the Island whereas $\mathrm{S}$. hunti was collected from the Acacia nilotica forest only of the total collections, P. orientalis representing 3.80\% (248 specimens) of the total collection and P. papatasi were $3.11 \%$ of the collection. Sand flies identification was done under a binocular microscope at 40x (magnification). The main features used for sand flies identification were the sperm theca of the female, the termination of the male and the pharyngeal and the ciboria toothed structures of both sexes. According to results of this study we recommended the following: more studies are needed in the future to determine the transmission season, and infection rates of Leishmania parasites in human and the animal host in this area. Annually Entomological surveys must be done to determine density of Sand fly Vectors and Encourage the use of personal protection tools (ITNs), repellents, and improving of houses to avoid bite of sand fly.
\end{abstract}

Keywords: Identification; Survey; Sand Flies; Collection; Leishmaniasis; El-Kadaba Village. 
Cite This Article: Belal Abdallah A. Adam, Moawia Mukhtar Hassan, Osman Mohammed Abd elnour, and Ahmed Hamid Awadallah. (2017). "INVESTIGATION OF LEISHMANIASIS VECTORS IN EL-KADOBA VILLAGE, WHITE NILE STATE, SUDAN." International Journal of Research - Granthaalayah, 5(1), 430-441.

\section{Introduction}

The Leishmaniasis is wide spread group of diseases worldwide. The disease is caused by obligatory, intracellular, kinetoplastid protozoan parasites of the genus Leishmania, which are transmitted by sandflies as flagellated promastigotes. Depending on the Leishmania species and the immune response of the host, the disease manifests itself in a variety of clinical forms; cutaneous (CL), mucocutaneous (MCL) and visceral leishmaniasis (VL).

Leishmaniasis is endemic in 88 countries on four continents: Africa, Europe, Asia, Central and Latin America (WHO, 1998). It is estimated that approximately 12 million people are currently infected and 350 million are at risk of acquiring leishmaniasis in 88 countries. The annual incidence rate is estimated to be 1.5-2 million cases of cutaneous leishmaniasis and 500,000 cases of visceral leishmaniasis (WHO, 2006).

Visceral leishmaniasis (VL; kala-azar) is the most severe form of the disease, which is fatal if untreated with an almost $100 \%$ mortality rate. The disease is characterized by irregular fever, loss of weight, splenomegaly, hepatomegaly and/or lymphadenopathy and anaemia.

Visceral leishmaniasis is caused by L. donovani on the Indian subcontinent and in East Africa, by L. infantum in the Mediterranean region and by L. chagasi, in the New World (Desjeux, 1991). Ninety percent of VL cases occur in India Brazil, and Sudan (WHO, 2006).

Cutaneous leishmaniasis (oriental sore) is an endemic disease in northern Africa and western and central Asia. The disease produces skin lesions, on the face, arms and legs, causing serious disability and permanent scars (WHO, 2006). The disease is caused by L. major, L. tropica and L. aethiopica in the Old World whereas, in the New World is caused by L. maxicana and L. braziliensis complexes.

Ninety percent of all cases of CL occur in Afghanistan, Brazil, Iran, Peru, Saudi Arabia and Syria, with 1-1.5 million new cases reported annually world-wide (WHO, 1996).

It is less common, chronic form of disease in evolution and especially difficult to treat. The disease produces lesions resembling leprosy, which do not heal spontaneously, due to deficiency of the immune response (Desjeux, 1996; WHO, 1998). DCL is due to L. aethiopica and L. amazonensis (Desjeux, 1996).

Muco-cutaneous leishmaniasis (espundia) produces disfiguring lesions to the face, destroying the mucous membranes of the nose, mouth and throat (WHO, 1998; 2006). The disease is mostly caused by L. braziliensis, L. panamensis and L. guyanensis in the New World, but mucosal lesions have been reported in the Old World due to L. donovani, L. major and L. infantum in immunosupresed patients (Desjeux, 1996). 
Post kala-azar dermal leishmaniasis (PKDL) is most frequent in the Indian subcontinent and East Africa where the parasite causing visceral leishmaniasis is Leishmania donovani and is rare in areas endemic for other viscerotropic Leishmania parasites (El-Hassan \& Zijlstra , 2001b). It was characterized by the occurrence of skin lesions, macules papules or nodules, mainly on the face, developing 2-7 years after apparently successful treatment of visceral leishmaniasis (VL).

Recently, HIV/Leishmania co-infections are considered to be a real threat, especially in southern Europe (WHO, 2006) because VL accelerates the onset of full-blown AIDS, and shortens the life expectancy of HIV-infected people, while HIV spurs the spread of VL.

Sudan is considered to be one of the areas of leishmaniasis in the world where recent epidemics had occurred with high incidence rates. The three clinical forms of leishmaniasis occur in Sudan e.g. VL including PKDL, CL and MCL (Fig. 1).

Sudan is considered to be one of the most important foci of VL in the world (Zijlstra and ElHassan, 2001a). Nowadays VL spreads over a wide belt from the Atbara River in the north east along the Sudanese-Ethiopian border to south of the Sobat River and Nassir and Malakal and extending to the west across the White Nile. Other foci are Kapoeta area, Nuba Mountains and scattered foci in Darfur region (Zijlstra and El-Hassan, 2001a).

Visceral leishmaniasis has been described in Sudan since the beginning of the twentieth century (Neave, 1904), with recent kala-azar epidemic in a relatively small area in the western Upper Nile Province in southern Sudan that claimed the lives of 100,000 out of a total population of 300,000 people (Seaman et al., 1996). Similarly, reports from two health centres operated by Medicin Sans Frontiers- Holland (MSF-Holland) stated that 3,200 cases of VL occurred annually in Gedarif State, eastern Sudan (Elnaiem et al, 2003).

In Sudan, VL is caused by Leishmania donovani complex: MON 18, MON 30 and MON 82 zymodemes (Ashford et al., 1992; Oskam et al., 1998). The proven vector is P. orientalis (Elnaiem et al., 2001; Hassan et al., 2008). Recently, P. orientalis was reported to occupy arid areas of northern Sudan (Hassan et al., 2008).

In Sudan, the VL is thought to be a zoonotic disease with some probable anthroponosis in epidemic situations (Desjeux, 1991). The idea that VL is a zoonotic disease was strongly accepted due to repeated outbreaks of VL in people camping in uninhabited woodlands of southern and eastern Sudan (Kirk, 1956). Furthermore, the finding of infected P. orientalis in the uninhabited Dinder National Park (DNP) strongly suggest the presence of a reservoir other than man (Hassan et al. 2008). This is supported by recent findings of possible L. donovani infections in dogs, Egyptian mongoose and other wild rats (Elnaiem et al., 2001, Dereure et al., 2003).

In Sudan, CL is endemic in several areas. The disease is caused by L. major (Andersen et al., 1996) although recently, L. donovani was isolated from CL lesions (Elamin et al., 2008). The disease is transmitted by P. papatasi (El-Sayed et al., 1991). The first cases of CL in Sudan were described at the beginning of the 20th century in two Egyptians who had contracted the disease in their country (Kirk and Drew 1938). However, the first reported CL case in a Sudanese patient was reported from the Nuba Mountains (Zijlstra and El-Hassan, 2001a). So far, three outbreaks 
of CL have been reported: the first started in 1976-77 in Shendi-Atbara north of Khartoum, the second 1985 in and around EI-Garasa in the White Nile area, and the last major epidemic took place in Khartoum Province (El-Safi et al., 1991). Currently, in 1990-1992 the disease spread along the River Nile up to Dongola and Mahas near the border with Egypt (El-Hassan and Zijlstra, 2001a).

Sudanese mucosal leishmaniasis (MSL) occurs as sporadic cases, less than 100 cases have been described up to date. The disease is caused by L. donovani or, less frequently, by L. major (ElHassan and Zijlstra, 2001b).

Post kala-azar dermal leishmaniasis is a complication of VL of unknown cause (Zijlstra and ElHassan, 2001b). This form of the disease particularly causes frequent problems in Sudan, where it develops in more than $50 \%$ of VL cases who appear to have been successfully treated (Zijlstra and El-Hassan, 2001b).

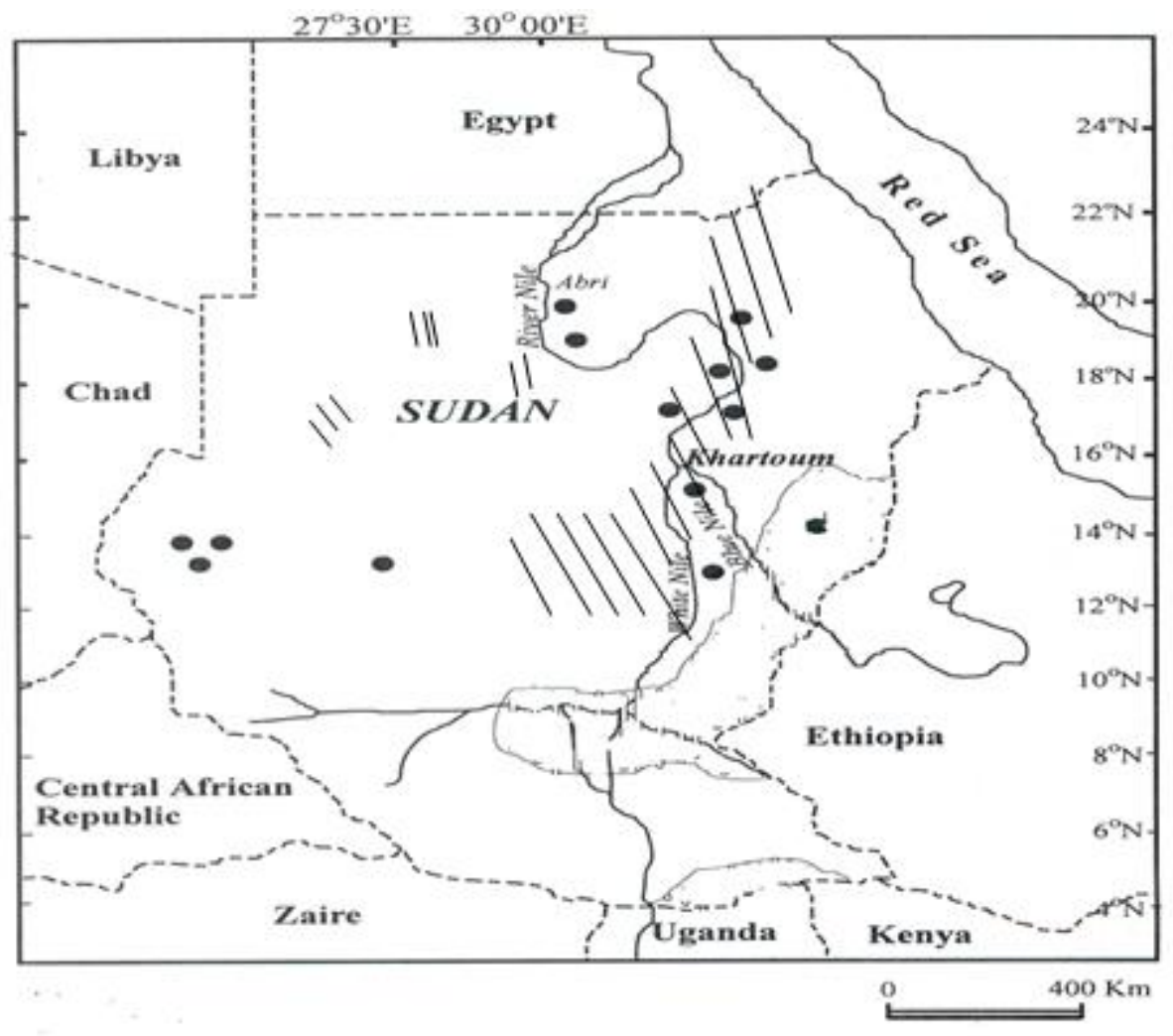

// Visceral leishmaniasis

- Cutaneous leishmaniasis

Figure 1: Distribution of cutaneous and visceral leishmaniasis in Sudan (After Hassan et al., 2008) 


\section{Material and Methods}

\subsection{Study Area}

El-Kadaba village is located on western bank of the White Nile River (White Nile State) (32 o $14^{\prime} \mathrm{E}, 14 \mathrm{o} 72^{\prime} \mathrm{N}$ ), it distances about $200 \mathrm{~km}$ south of Khartoum (capital of Sudan). The area is flat and covered by an alluvium of silt clay soil of the two types, black cracking clay soil and sand deposited by the river. Climate of it resembles a semi desert region therefore it is part of the arid climate with three distinct seasons; winter (November-February), summer (March-June) and autumn (July-Octobor) with an estimated annual rainfall of $<400 \mathrm{~mm}$.

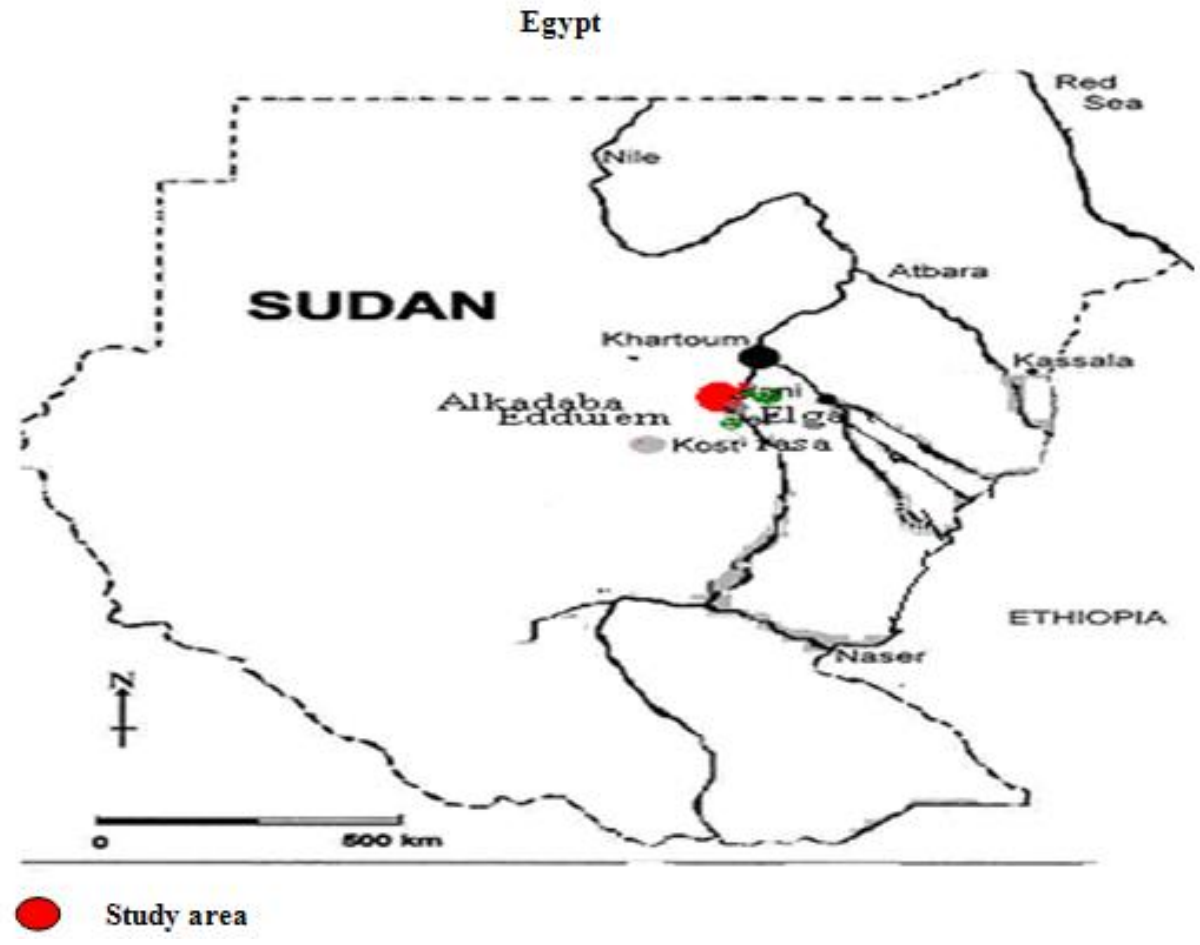

Figure 2: Map showing location of the study area

\subsection{Sample Size}

In this study about 6527 sandflies were collected from diferent habitats during all the period of survey, during period of survey, about 52 females of sandflies were dissected to investigate about Leishmania promastigotes. These dissected species are: 35 flies were P. orientalis, 16 were P. papatasi and one female was $\mathrm{P}$. rodhaini.

\subsection{Data Collection}

\subsubsection{Light Traps}

The light traps used to collect nocturnally active sandflies were CDC miniature light traps (Model 512, John Hock Co., Gainesville, Florida, USA), connected to 6volts rechargeable 
batteries and sandflies cages (Plate 2). The light traps were generally hanged at $30 \mathrm{~cm}$ above the ground level at outdoor and indoor sites, between 18:00-06:00 HR. Captured sandflies were separated from other insects and preserved in $70 \%$ alcohol for identification.

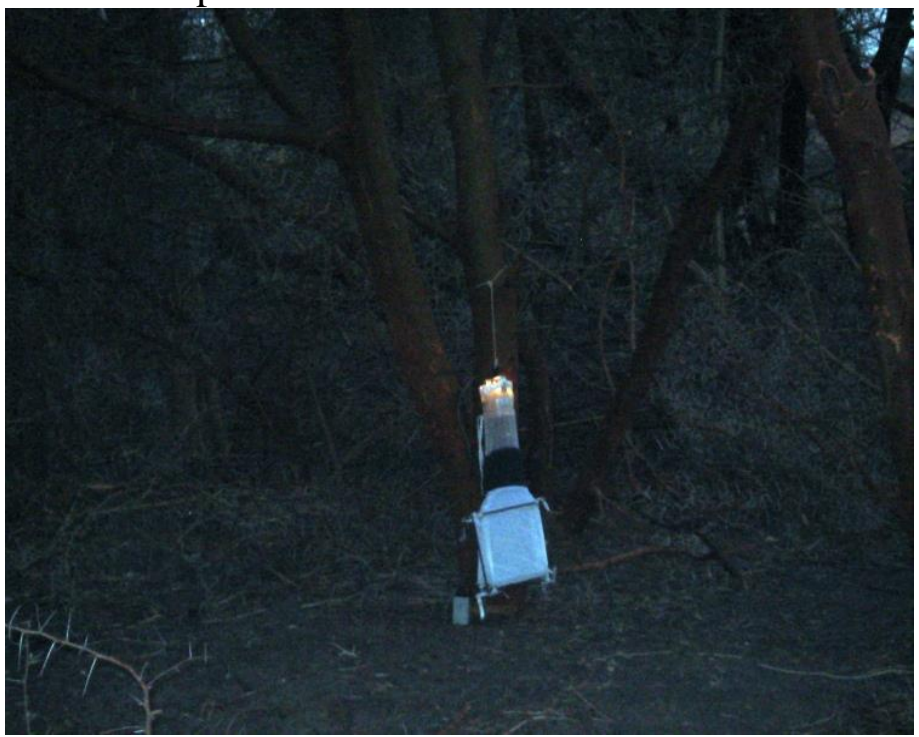

Plate 1: CDC miniature traps used for sandflies collection during July 2008

\subsubsection{Sticky Paper Traps}

The sticky paper traps were xerox paper sheets $\left(15 \times 21 \mathrm{~cm}^{2}\right)$ coated on both sides with diesel oil or caster oil and fixed vertically on sticks held at $15 \mathrm{~cm}$ above the ground (Plate 3) and left overnight from 18:00-06:00 HR and collected by the next morning. Sandflies found stuck on the oiled papers were removed using small brushes, washed in dilute detergent and preserved in $70 \%$ alcohol for identification.

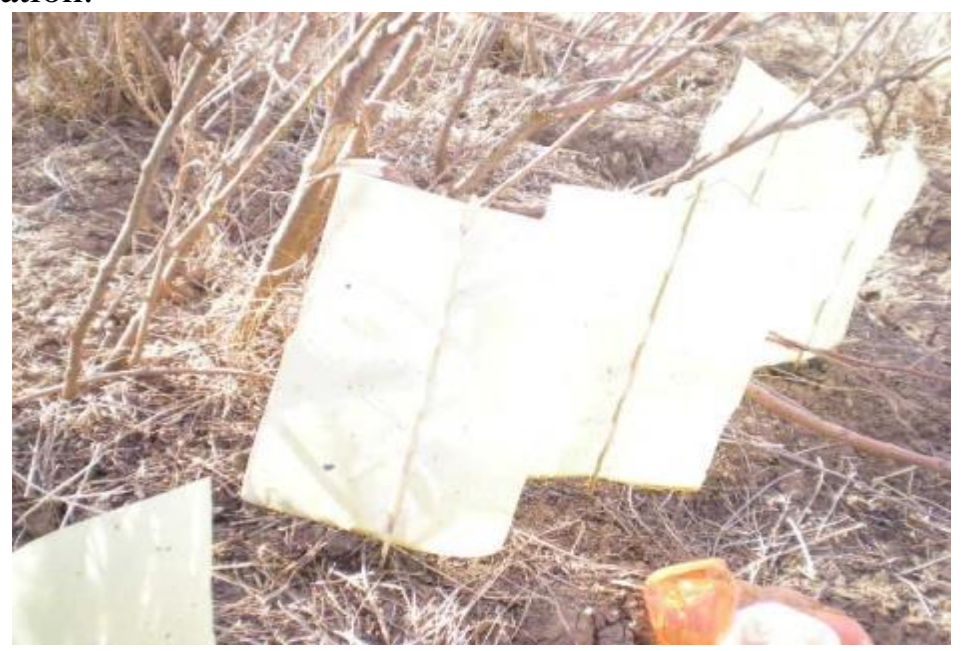

Plate 2: Sticky paper traps used for sandflies collection during July 2008

\subsubsection{Data Analysis}

Obtained Data was analyzed by a computer through the program (SPSS) and excel program. Then presented in tables and figures. 


\section{Results}

Ten species of sandflies were recorded, three Phlebotomus species and seven Sergentomyia species namely: Phlebotomus papatasi, P. orientalis, P. rodhaini Sergentomyia clydei, S. schwetzi, S. antennatus, S. squamipleuris, S. africana, S. sintonious and S. hunti.

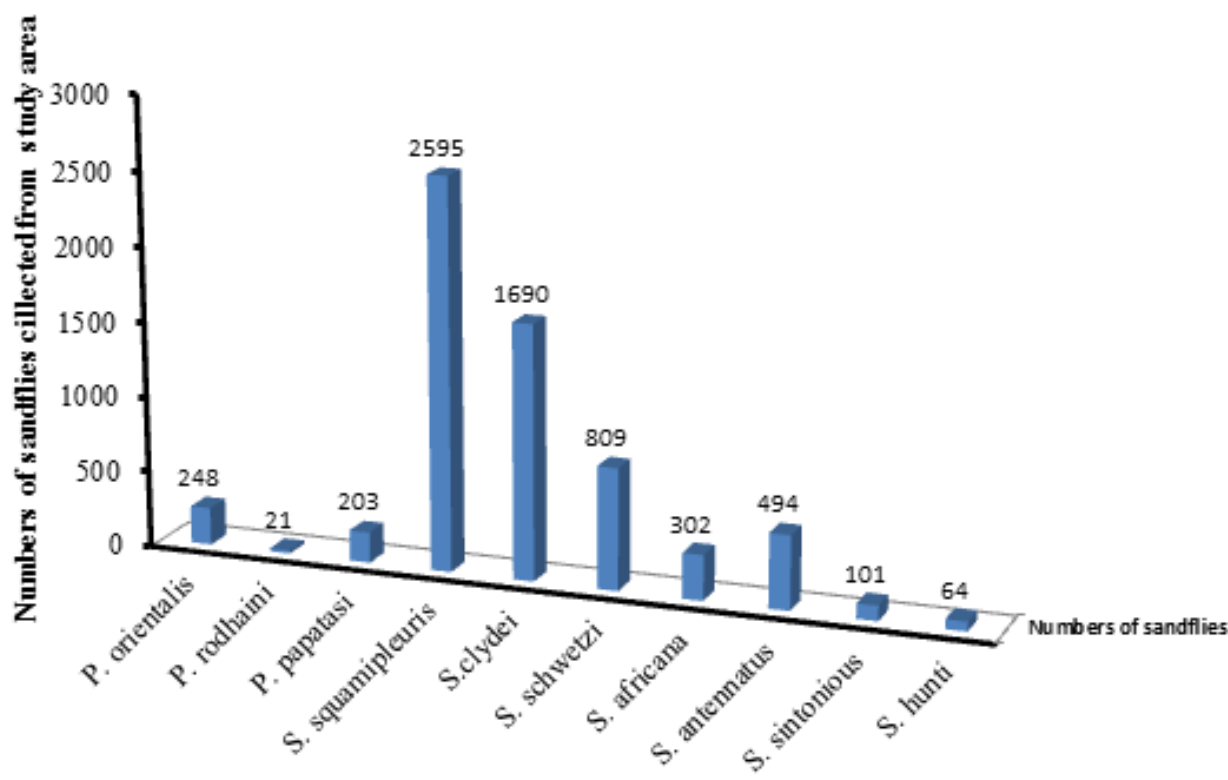

Sandfly species

Figure 3: species of sand flies collected from study area during July 2008

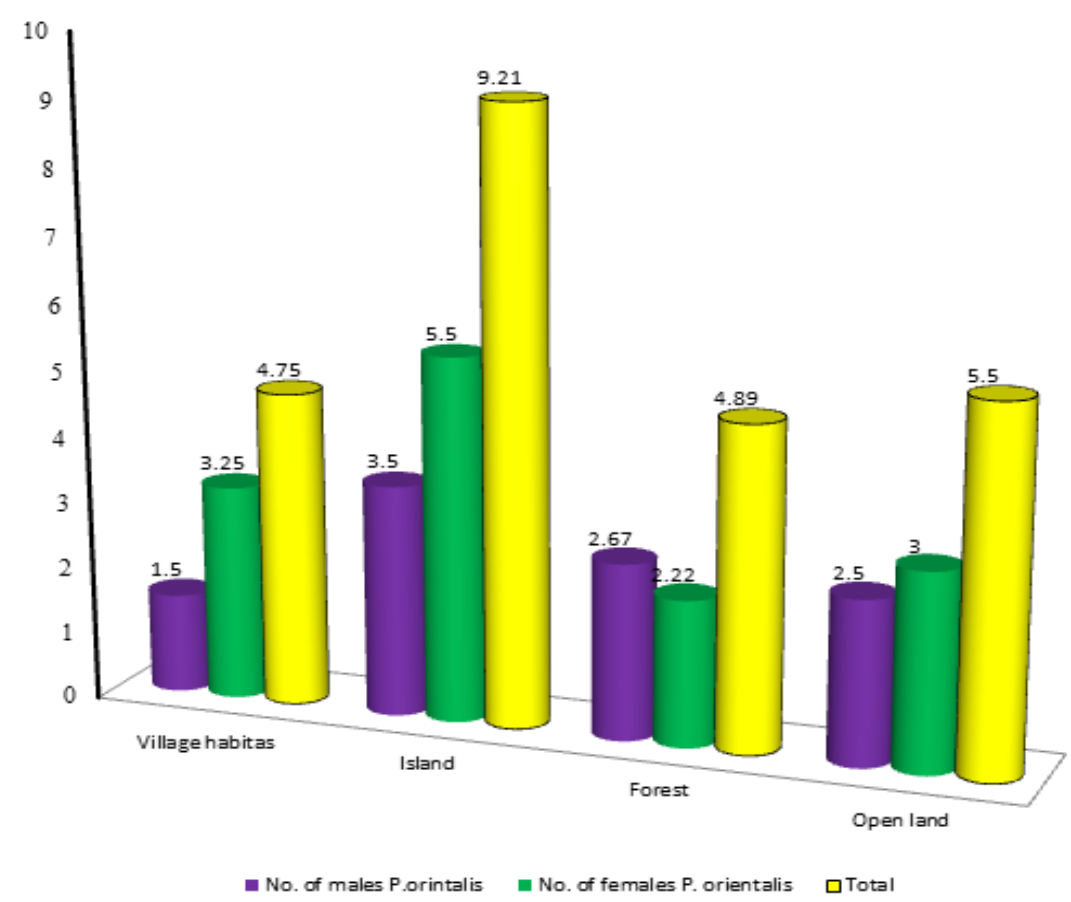

Figure 4: the above figure shows that the abundance of Phlebotomus orientalis is higher in island than other habitats also density of female higher than male in all habitats except in forest 
Table 1: density of sand fly species in two habitats in study area during July 2008

\begin{tabular}{|l|l|l|l|}
\hline \multirow{2}{*}{ Species } & Mean \pm SE / oil trap in habitats & P.value \\
\cline { 2 - 4 } & $\begin{array}{l}\text { Grass Island near the } \\
\text { river }\end{array}$ & A.seyal/B.aegyptiaca & \\
\hline P. orientalis & $0.40 \pm 0.18$ & $4.00 \pm 1.21$ & 0.00 \\
\hline P. papatasi & $2.40 \pm 0.11$ & $2.00 \pm 0.56$ & 0.00 \\
\hline S. squamipleuris & $28.80 \pm 3.25$ & $16.25 \pm 2.16$ & 0.00 \\
\hline S. clydei & $9.60 \pm 1.13$ & $13.50 \pm 1.97$ & 0.07 \\
\hline S. schwetzi & $6.80 \pm 0.66$ & $8.00 \pm 2.43$ & 0.60 \\
\hline S. Africana & $0.40 \pm 0.18$ & $3.25 \pm 0.62$ & 0.00 \\
\hline S. antennatus & $0.00 \pm 0.00$ & $11.00 \pm 1.34$ & 0.00 \\
\hline S. hunti & $0.00 \pm 0.00$ & $4.00 \pm 0.82$ & 0.00 \\
\hline
\end{tabular}

The above table shows that species of Sergentomyia are found with high numbers more than other genus and $\mathbf{S}$. squamipleuris was the highest density in both habitats.

Table 2: Comparison between the abundance of Phlebotomus orientalis in different habitats at study area during July 2008

\begin{tabular}{|l|l|l|l|}
\hline \multirow{2}{*}{$\begin{array}{l}\text { Site of collection of } \\
\text { sandflies }\end{array}$} & \multicolumn{2}{|l|}{ Total } \\
& $\begin{array}{l}\text { M } \pm \text { SE Number of } \boldsymbol{P} \text {. orientalis collected } \\
\text { with sticky paper trap }\end{array}$ & \\
\cline { 2 - 3 } & Male & Female & \\
\hline Village & $1.50 \pm 0.20$ & $3.25 \pm 0.72$ & $4.75 \pm 0.94$ \\
\hline Island & $3.50 \pm 0.51$ & $5.50 \pm 0.97$ & $9.00 \pm 0.1 .46$ \\
\hline Forest & $2.67 \pm 0.451$ & $2.22 \pm 0.61$ & $4.89 \pm 0.96$ \\
\hline Open-land & $2.50 \pm 0.43$ & $3.00 \pm 0.58$ & $5.50 \pm 0.92$ \\
\hline P value & 0.064 & 0.01 & 0.021 \\
\hline
\end{tabular}

The above table shows that $P$. orientalis are indicated statistical significant according to $P$. value (less than 0.05 ) and female of $P$. orientalis more than male in all habitats except in forest. 


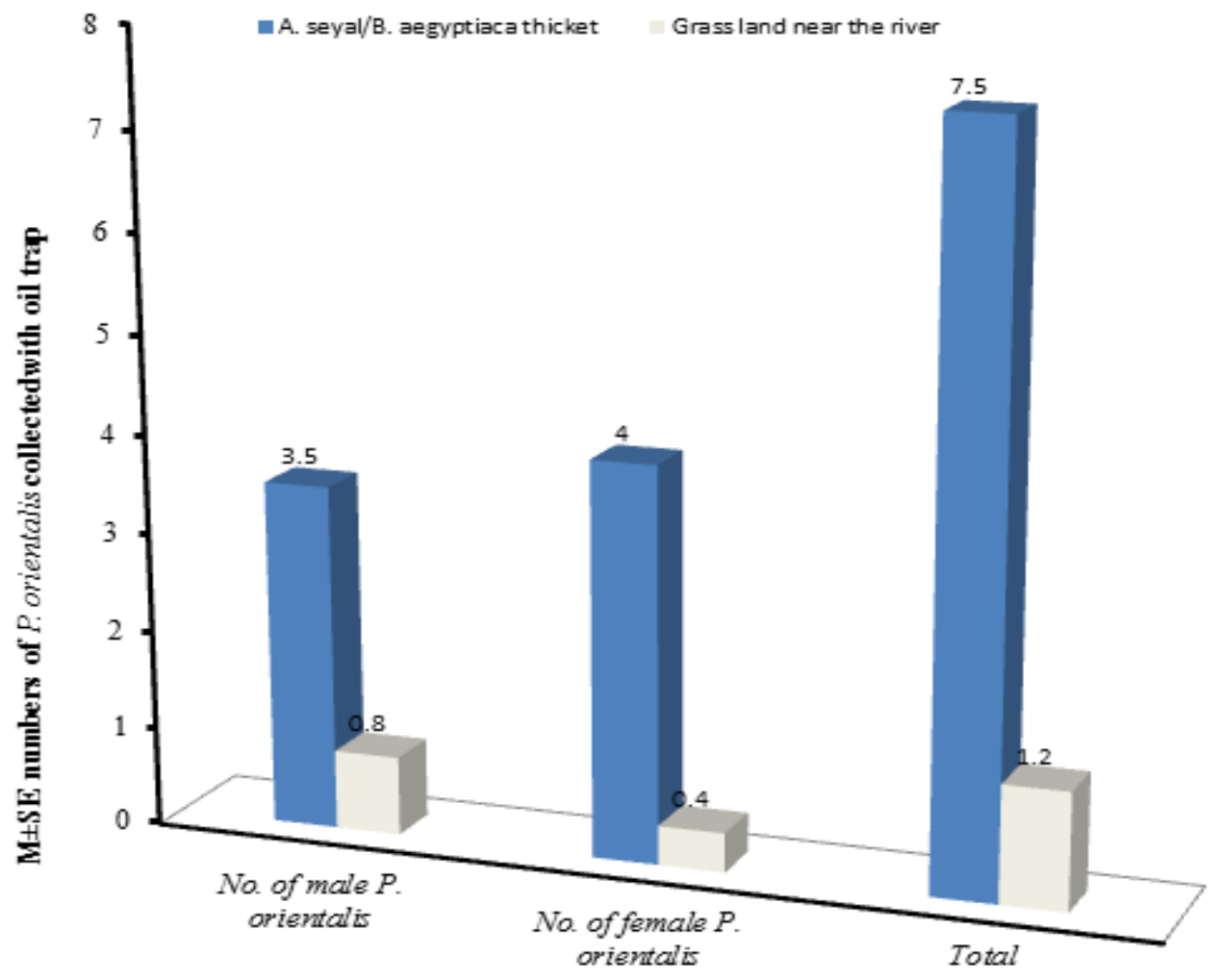

Figure 5: The above figure shows that the abundance of female of Phlebotomus orientalis in forest is higher than male while male of Phlebotomus orientalis in grass is higher than female

\section{Discussion}

The study found that sand flies collected from different habitats at El-Kadaba village and its surrounding during July 2008. Using one-way ANOVA, the P. orientalis were collected

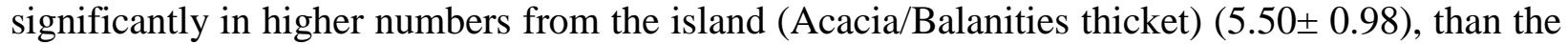
village (3.25 \pm 0.72$)$, the open-land $(3.0 \pm 0.58)$ and the forest of A. nilotica $(2.22 \pm 0.61)$. No significant differences were observed in the numbers of P. papatasi collected from all sites. Sergentomyia squamipleuris, S. clydei, S. antennatus and S. africana were significantly collected in higher numbers from the island than village, forest and open land. Sergentomyia schwetzi

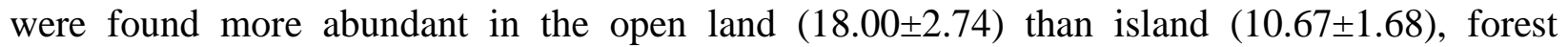
$(8.11 \pm 1.06)$ and village habitats, figure (3).

The current study revealed that numbers of Phlebotomus sand flies dissected in El-Kadaba village and its surrounding habitats were not Leishmania promastigotes carrier, after dissected about 52 females of sand flies during period of survey, these dissected species are : 35 flies were P. orientalis, 16 were P. papatasi and one female was P. rodhaini. None of all these species were found infected with Leishmania promastigotes.

The morphological features of P. orientalis collected during this study were similar to those of the corresponding species reported by Kirk and Lewis (1951) and Quate (1964). The record of P. orientalis vector in the northern Sudan was a unique phlebotominae finding in this area. The presence of this sandfly vector which typically inhabits savannah environments in northern 
Sudan is very interesting from a biogeographical distribution viewpoint. Therefore, in the future more systematic studies are needed to determine their geographic distributions, to compare their seasonality and to elucidate their transmission potential. Also, the presence of P. orientalis in northern Sudan could indicate continuous changes in the environmental determinants of this vector species and the possibility of new foci of VL in Sudan in the future.

The results obtained on the infection rates of the sandfly vectors with Leishmania parasites revealed that no infection was detected among the Phlebotomus sandflies dissected during July 2008. This may be due to low transmission rates in White Nile VL endemic focus. It is known that the detection of the Leishmania parasites in sandflies is laborious becuase large numbers of flies must be dissected in the field. Moreover, the knowledge on the transmission season of VL in this area is lacking therefore it may be the reason that no Leishmania infection was detected in sandflies during this survey although most of the previous studies in other VL endemic foci in Sudan showed that the transmission season occur between May-July (Ashford et al., 1992; Elnaiem et al., 1998a).

The reappearance of VL cases during 2006-2007 indicates the maintenance of the transmission cycle most probably through reservoir host, however the role of asymptomatic human cases in maintenance of the parasite can't be ruled out.

\section{Conclusion}

1) The sandflies species found in the area consists of three Phlebotomus and seven Sergentomyia species which are namely P. orientalis, P. papatasi, P. rodhaini, Sergentomyia clydei, S. schwetzi, S. antennatus, S. squamipleuris, S. africana, S. sintanious and S. hunti.

2) S. squamipleuris, S. clydei and S. schwetzi were the most dominant species in the area.

3) P. orientalis were collected from all habitats in the area.

4) P. rodhaini was collected only from the woodland of Acacia seyal/Balanities aegyptiaca in the Island near El-Kadaba village.

5) P. orientalis was absent from indoor sites of El-Kadaba village.

6) P. orientalis, is the only proved sand fly vector of VL, was collected from study area.

7) All females of sand fly vectors that dissected were not infected by Leishmania promastigotes.

\section{Recommendations}

According to results of this study it is recommended that. :

Annually Entomological surveys must be done to determine density of Sand fly Vectors by seasons and to determine the transmission season, and infection rates of Leishmania parasites in human and the animal host in this area , Encourage the use of personal protection tools (ITNs), repellents, and improving of houses to avoid bite of sand flies, and Control of Leishmaniasis procedures must be directed towards reservoirs, mass treatment of patients, and Vectors. 


\section{Acknowledgments}

The authors are would like to thank and grateful to all those who have helped and contributed in making this study a success.

\section{References}

[1] Andresen, K., Ibrahim, M. E., Theander, T. G. and Kharazmi, A. (1996). Random amplified polymorphic DNA for the differentiation of Leishmania isolates from Sudan. Transactions of the Royal Society of Tropical Medicine and Hygiene, 90: 204-205.

[2] Ashford, R. W., Seaman, J. and Schorscher, J. (1992). Epidemic visceral leishmaniasis in southern Sudan: identification and systematic position of the parasites from patients and vectors. Transaction of the Royal Society of Tropical Medicine and Hygiene. 86: 379-380.

[3] Deruere, J., El-Safi, S. H., Bucheton, B., Boni, M., Kheir, M. M., Davoust, B., Pratlong, F., Feugier, E., Lambert, M., Dessein, A. and Dedet, J. P. (2003). Visceral leishmaniasis in eastern Sudan: parasite identification in humans and dogs; host-parasite relationships. Microbes Infections, 5(12):1103-1108.

[4] Desjeux, P. (1991). Information on the epidemiological and control of leishmaniasis by country or territory. WHO/ LEISH/ 91. 30.

[5] Desjeux, P. (1996). Leishmaniasis. Public health aspects and control. Clinical Dermatology, 14: 417-423.

[6] Elamin E. M., Guizani I., Guerbouj S., Gramiccia M., El-Hassan A. M., DiMuccioo T. Taha M. A. and Mukhtar M. M. (2008). Identification of Leishmania donovani as a cause of cutaneous leishmaniasis in Sudan. Transactions of the Royal Society of Tropical Medicine and Hygiene, 102(1): 54-7.

[7] El-Hassan A. M and Zijlstra, E. E. (2001a). Leishmaniasis in Sudan. Cutaneous leishmaniasis. Transaction of the Royal Society of Tropical Medicine \& Hygiene, 95 (Suppl 1): S1-17.

[8] El-Hassan A. M and Zijlstra, E. E. (2001b). Leishmaniasis in Sudan. Mucosal leishmaniasis. Transaction of the Royal Society of Tropical Medicine and Hygiene, 95 (Suppl 1): S19-26

[9] Elnaiem, D. A., Hassan, M. M., Maingon, R., Nureldin, G. H., Mekawi, A. M., Miles, M. and Ward, R. D. (2001). The Egyptian mongoose, Herpestes ichneumon, is a possible reservoir host of visceral leishmaniasis in eastern Sudan. Parasitology, 122(5): 531-536.

[10] Elnaiem, D. A., Schorscher, J., Bendall, A., Obsomer, V., Osman, M. E., Mekkawi, A. M., Connor, S. J., Ashford, R. W. and Thomson, M. C. (2003). Risk mapping of visceral leishmaniasis: the role of local variation in rainfall and altitude on the presence and incidence of kala-azar in eastern Sudan. American Journal of Tropical Medicine and Hygiene, 68(1): 10-17.

[11] El-Safi, S. Peters, W., El Toam, B., El Kadaro, A. and Evans, D. A. (1991). Studies on the leishmaniasis in Sudan. 2. Clinical and parasitological studies on cutaneous leishmaniasis. Transactions of the Royal Society of Tropical Medicine and Hygiene, 85: 457-464.

[12] El-Sayed, S. M., El Raaba, F. M. and Abd el Nur, O. (1991). Daily and seasonal activities of some sandflies from Surrugia village, Khartoum, Sudan. Parassitologia, 33 (Suppl): 205-15.

[13] Hassan, M. M., Elamin, W. M. and Mukhtar, M. M. (2008). Isolation and identification of Leishmania donovani from Phlebotomus orientalis, in an area of eastern Sudan with endemic visceral leishmaniasis. Annals of Tropical Medicine and Parasitology, 102(6), 1-3.

[14] Kirk, R. (1956). Studies in leishmaniasis in the Anglo-Egyptian Sudan. XII. Attempt to find reservoir host. Transaction of the Royal Society of Medicine and Hygiene, 50: 169-177

[15] Neave, S. H. M. (1904). Leishmania donovani in Sudan. British Medical Journal, i, 1252.

[16] Oskam, L. Pratlong, F., Zijlstra, E. E., Kroon, C. C. M., Dedet, J. P., Kager, P. A., Schonian, G., Ghalib, H. W., El-Hassan, A. M. \& Meredith, S. E. O. (1998). Biochemical and molecular 
characterization of Leishmania parasites isolated from endemic focus of eastern Sudan. Transactions of the Royal Society of Tropical Medicine and Hygiene, 92: 120-

[17] Quate, L. W. (1964). Leishmaniasis in Sudan Republic. 19. Phlebotomus sandflies of the Paloich area in the Sudan (Diptera; Psychodidae). Journal of Medical Entomology, 1: 213-268.

[18] WHO report, (2006). Control of leishmaniasis. Executive Board 11 8th session.

[19] WHO (1998). Leishmania and HIV in gridlock. WHO/UNAIDS report. . Geneva: World Health Organization. 15-25.

[20] WHO, (1996). Manual on visceral leishmaniasis control. Geneva, World Health Organization. WHO/Leish/96. 40: 1-76.

[21] WHO (1990). Control of the leishmaniasis. Technical Report Series 793, World Health Organisation, Geneva, Switzerland.

[22] Zijlstra, E. E, and El-Hassan A. M. (2001a). Leishmaniasis in Sudan. visceral leishmaniasis. Transaction of the Royal Society of Tropical Medicine and Hygiene, 95 (Suppl 1): S27-58.

[23] Zijlstra, E. E, and El-Hassan A. M. (2001b). Leishmaniasis in Sudan. Post kala-azar dermal leishmaniasis. Transaction of the Royal Society of Tropical Medicine and Hygiene, 95 (Suppl 1): S59-76.

*Corresponding author.

E-mail address: belalabdo011@ush.sd 